\title{
Outcomes of interrupted aortic arch repair using the carotid artery turndown procedure
}

\author{
Steven H. Todman, MD, ${ }^{\mathrm{a}}$ Osama Eltayeb, MD, ${ }^{\mathrm{b}}$ Mark Ruzmetov, MD, PhD, ${ }^{\mathrm{b}}$ Mark D. Rodefeld, MD, \\ Mark W. Turrentine, MD, ${ }^{\mathrm{b}}$ John W. Brown, MD, ${ }^{\mathrm{b}}$ and John P. Breinholt, MD ${ }^{\mathrm{a}}$
}

Objective: Interrupted aortic arch is a rare congenital anomaly affecting $1.5 \%$ of infants with congenital heart disease. Multiple surgical modalities exist to address this defect. We evaluate the long-term outcome of interrupted aortic arch with the left carotid artery turndown technique from a single institution.

\begin{abstract}
Methods: Patients with interrupted aortic arch who underwent the carotid turndown procedure were identified between September 1982 and March 2010. Medical and surgical records were reviewed. Mortality data were obtained from state death records.
Results: Forty-seven patients met inclusion criteria. Median follow-up was 6.2 years (5 days to 23.2 years). Twenty-one patients $(45 \%)$ had genetic syndromes. There were 4 operative deaths $(8.5 \%)$ and 9 late deaths $(19 \%)$. One-year and 5-year survivals were $80.2 \%$ and $72.6 \%$, respectively. Seventeen patients $(36.2 \%)$ re- quired reoperation or other interventions on the aortic arch.

Conclusions: Left carotid artery turndown offers a favorable surgical outcome. It compares with end-to-end repair, while providing a tension-free anastomosis and avoiding neonatal circulatory arrest and cardiopulmonary bypass. Disadvantages include a 2 -stage repair and a significant reintervention rate, particularly when compared with the aortic arch advancement technique. Nevertheless, the reduced exposure to circulatory arrest and bypass and avoidance of left bronchial obstruction are important considerations that may offset these limitations. (J Thorac Cardiovasc Surg 2013;145:176-82)

Interrupted aortic arch (IAA), first described by Steidele in $1778,{ }^{1}$ is a rare cardiac anomaly in which discontinuity exists between the ascending and descending aortas. ${ }^{2}$ IAA accounts for approximately $1.5 \%$ of all infants with congenital heart disease, and without medical intervention, its natural history results in an $80 \%$ mortality rate during the first month of life. ${ }^{2}$ Medical management was revolutionized with the introduction of prostaglandin E1 in 1976. ${ }^{3,4}$

Since the first surgical repair in 1955 , multiple techniques have been used. ${ }^{5}$ Regardless of method, reintervention is frequently required to address recurrent aortic arch obstruction. ${ }^{6}$ Other significant sources of reintervention include left ventricular outflow tract obstruction ${ }^{7}$ and left bronchial compression. ${ }^{8}$

At the Indiana University School of Medicine, the primary method of IAA repair has been the left carotid artery turndown (LCATD) technique. The aim of this study was to

From the Department of Pediatrics (Cardiology) a and Department of Cardiovascular and Thoracic Surgery, ${ }^{\mathrm{b}}$ Indiana University School of Medicine, Indianapolis, Ind. Disclosures: Authors have nothing to disclose with regard to commercial support.

Read at the 37th Annual Meeting of The Western Thoracic Surgical Association, Colorado Springs, Colorado, June 22-25, 2011.

Received for publication June 21, 2011; revisions received Aug 13, 2012; accepted for publication Sept 12, 2012; available ahead of print Oct 8, 2012.

Address for reprints: John P. Breinholt, MD, Riley Hospital for Children, 705 Riley Hospital Drive, RR127, Indianapolis, IN 46202 (E-mail: jpbreinh@iupui.edu).

$0022-5223 / \$ 36.00$

Copyright (c) 2013 by The American Association for Thoracic Surgery

http://dx.doi.org/10.1016/j.jtcvs.2012.09.018 evaluate the long-term outcome of this surgical technique and to compare this method with other reported surgical modalities.

\section{MATERIALS AND METHODS}

All patients with the diagnosis of IAA who underwent repair by LCATD at the James W. Riley Hospital for Children between September 1982 and July 2009 with follow-up through June 2010 were identified after institutional review board approval. Hospital medical and surgical records were reviewed, as well as the medical and surgical records from the divisions of pediatric cardiology and cardiothoracic surgery. Data collected include patient demographics, nature of cardiac disease and associated syndromes, surgical and catheterization reports, echocardiograms, and clinical followup. Additional information regarding mortality was obtained through state death records. Operative mortality was defined as any death occurring within 30 days of the carotid turndown procedure or after 30 days during the same hospitalization. Subsequent deaths were defined as late mortality. Survival time was defined as elapsed time since the date of surgery until death or day of last follow-up. The Celoria and Patton classification was used to determine IAA type.

\section{Surgical Procedure}

Reconstruction of the aortic arch by the LCATD is performed by anastomosing the divided and spatulated end of the distal left carotid artery to the descending aorta, with division and excision of the patent ductus arteriosus via a left thoracotomy. Pulmonary artery (PA) banding also is performed as part of this staged approach. ${ }^{10}$

After the left carotid artery, transverse aortic arch, left subclavian artery, and ductus arteriosus are circumferentially dissected, the descending thoracic aorta is mobilized distally for 4 to 6 pairs of intercostal arteries. The left common carotid artery is then mobilized as far cranially as possible, and the ductus arteriosus is ligated and divided, with removal of ductal tissue from the distal aortic arch. The left common carotid artery is then 


\section{Abbreviations and Acronyms \\ CHSS = Congenital Heart Surgeons' Society \\ CI = confidence interval \\ IAA $=$ interrupted aortic arch \\ LCATD $=$ left carotid artery turndown \\ PA = pulmonary artery \\ VSD $=$ ventricular septal defect}

divided, spatulated, and anastomosed to the descending thoracic aorta with absorbable suture, as shown in Figure 1. ${ }^{10}$

The second stage of the procedure (typically 3-9 months later) comprises patch closure of the ventricular septal defect (VSD), repair of any additional intracardiac defects, PA debanding, and PA reconstruction with polytetrafluoroethylene or autologous pericardial patch. ${ }^{10}$ In complex congenital heart disease, particularly with single ventricle anatomy, alternate procedures are used as indicated for the subsequent stages.

\section{Statistical Analysis}

Survival and freedom from arch reintervention curves were constructed using the Kaplan-Meier product limit method and various percentiles, and $95 \%$ confidence intervals (CIs) were calculated. Freedom from reintervention was calculated as the elapsed time since the date of surgery to the date of reintervention. Subjects who died or were lost to follow-up before reintervention were censored at the time of death or date of last follow-up. Univariate Cox proportional hazards models were used to compare the various curves between eras of surgery and to evaluate various risk factors for late survival.

\section{RESULTS}

Forty-seven neonates and infants met inclusion criteria for the study. The median postoperative follow-up was 8.2 years (95\% CI, 6.2-12.2; range, 5 days to 23.2 years). Thirty patients $(64 \%)$ were male. Mean birth weight was $3.0 \mathrm{~kg} \pm 0.6 \mathrm{~kg}$. Genetic syndromes were diagnosed in 21 patients (45\%), with DiGeorge in $19(40 \%)$ and VACTERL association (disorder that involves abnormalities of the vertebrae, anus, heart, trachea, kidneys and limbs) in $2(4 \%)$. Forty-six patients $(98 \%)$ were classified as IAA type B, with 1 patient classified as IAA type A. The most common associated structural cardiac anomaly was a VSD, which was present in 46 patients (98\%). Twenty-seven patients $(57 \%)$ had an atrial septal defect. Nineteen patients $(40 \%)$ had a bicuspid or unicommisural aortic valve. Twelve patients $(26 \%)$ had subaortic stenosis, and 3 patients $(6 \%)$ had aortic valve stenosis. Two patients $(4 \%)$ had Taussig-Bing double-outlet right ventricle, and 3 patients $(6 \%)$ had an aberrant right subclavian artery. Baseline demographic data and associated structural cardiac anomalies are detailed in Table 1.

\section{Mortality}

Outcome evaluation for the first-stage LCATD procedure demonstrated no intraoperative deaths. Thirty-day survival for all patients was $95.7 \%(95 \% \mathrm{CI}, 83.9-98.9)$. There were $13(28 \%)$ total deaths in our patient cohort, including
2 intraoperative deaths during subsequent surgeries. Ten of 13 patients had IAA with a VSD or multiple VSDs. Three patients had complex lesions, including double-inlet left ventricle with ventricular inversion, dextro-transposition of the great arteries, and truncus arteriosus. Figure 2 illustrates the Kaplan-Meier survival for all patients. One-year, 5-year, and 15 -year survivals for all patients were $80.2 \%(95 \% \mathrm{CI}$, 65.4-89.2), 72.6\% (95\% CI, 56.6-83.5), and 67.4\% (95\% CI, 49.0-80.5), respectively. To determine whether there was as difference in mortality according to the date of surgery, the years of surgery were dichotomized at the median value into 2 eras: 1982 to 1995 and 1996 to 2009 (Figure 3). There were $6(46 \%)$ deaths in patients in the first era and $7(54 \%)$ deaths in patients after $1995(P=.62)$.

Four patients were classified as operative mortalities $(8.5 \%)$. Bacterial sepsis developed in 1 patient, who died 5 days after LCATD. One patient died 10 days after LCATD during a subsequent surgery that included a Damus-KayeStansel procedure, subaortic resection, and placement of a Sano-type right ventricle to PA conduit. The surgery was uneventful, with good hemodynamics maintained throughout the operation; however, there was significant residual transverse aortic arch obstruction at the end of the procedure. Given the extensive dissection at the site and the prior use of the carotid artery for aortic arch reconstruction, the surgeon determined that no further augmentation was possible; the patient was weaned from cardiopulmonary bypass and died shortly thereafter. One patient died 1.3 months after LCATD secondary to a central line infection and never achieved hospital discharge. One patient died 5.6 months after LCATD secondary to respiratory failure. This patient had VACTERL association with tracheoesophageal fistula and bronchomalacia. In addition to the 4 patients who experienced operative mortality, 1 patient was lost to follow-up after hospital discharge 8 days after surgery. There were 9 late mortalities after the patient lost to follow-up was excluded from the late survival analysis. Mortality data are described in Table 2. Censoring the survival data for these patients demonstrates similar findings.

Univariate analysis for various risk factors, including gender, birth weight, age at surgery, and genetic syndrome, did not identify significant associations with late mortality.

Thirty-two patients underwent the second-stage repair that included VSD closure and PA debanding at $1.7 \pm 2.3$ years after LCATD surgery (median, 0.9 years; range, 0.03-10.1 years). There were 2 operative mortalities associated with the second-stage surgery. By combining the 2 stages, operative mortality for this lesion was $12.8 \%$. In 1 patient with truncus arteriosus after PA band removal, VSD closure, and placement of a 12-mm aortic homograft right ventricle to PA conduit, the patient could not be weaned from cardiopulmonary bypass and died on the operative table. The second patient underwent PA band removal and VSD closure and was placed on extracorporeal membrane 

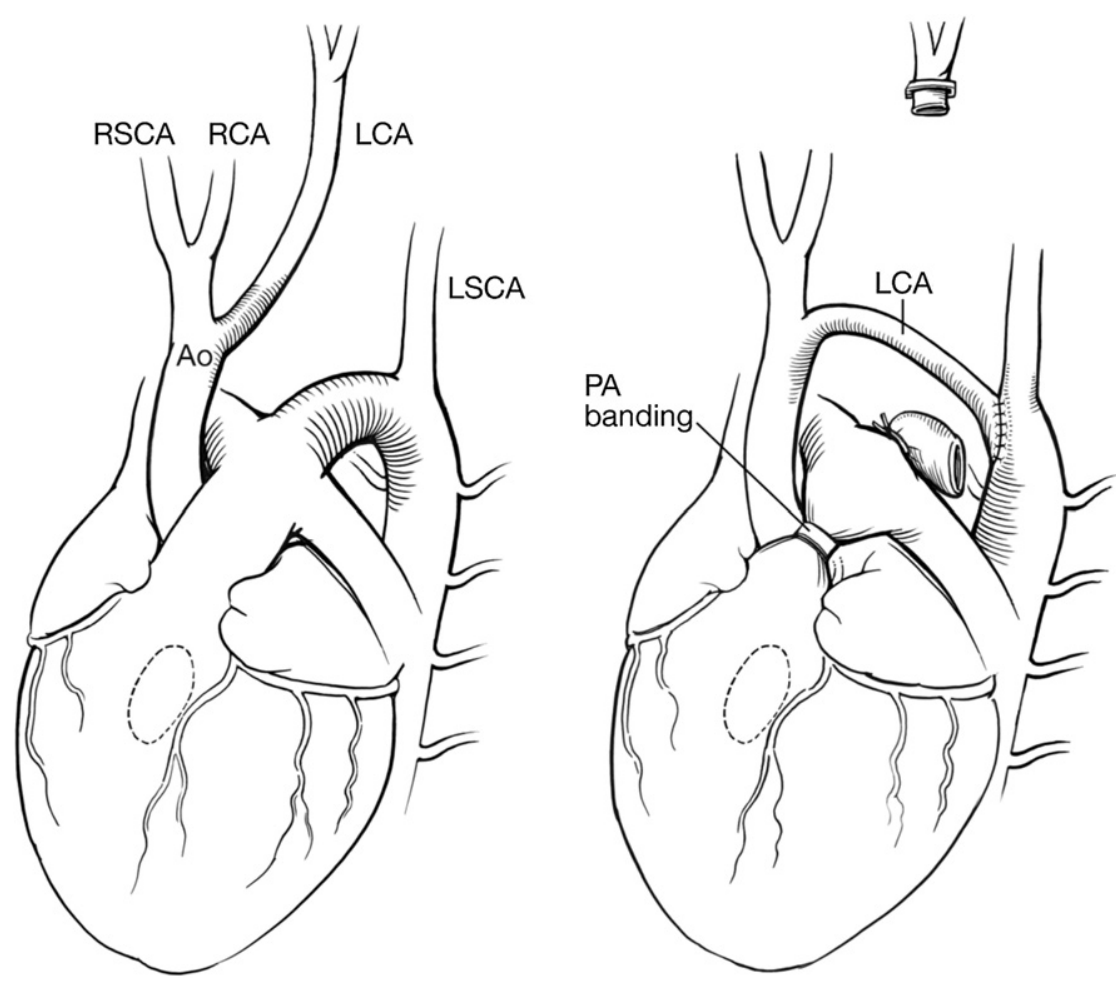

FIGURE 1. Left carotid artery turndown procedure. Ao, Aorta; $L C A$, left coronary artery; $L S C A$, left subclavian artery; $P A$, pulmonary artery; $R C A$, right coronary artery; $R S C A$, right subclavian artery.

oxygenation after surgery. The patient died 4 days later secondary to low-output heart failure. These surgeries occurred 2.3 and 3.3 months after LCATD surgery, respectively.

\section{Reintervention and Reoperation}

Seventeen patients $(36.2 \%)$ underwent surgical or interventional cardiac catheter-based aortic arch reinterventions, comprising angioplasty or placement of an endovascular stent. There were 8 surgical and 10 nonsurgical reinterventions, with 1 patient undergoing a surgical reintervention followed 9.5 years later by a catheter-based aortic arch intervention. Figure 4 illustrates the KaplanMeier freedom from aortic arch reintervention or reoperation data for all patients. The 30-day freedom from any type of arch reintervention or reoperation was $97.7 \%$ (95\% CI, 84.9-99.7) The 1-year and 15-year freedom from aortic arch reintervention or reoperation was $63.6 \%$ (95\% CI, 46.9-76.3) and 57.4\% (95\% CI, 40.2-71.2), respectively. There was no difference in survival when segmented into surgical era $(P=.23)$.

No patients in our series had left bronchial compression. Subaortic stenosis that required a subaortic membrane resection occurred in 6 patients $(12.8 \%) 1.4 \pm 1.0$ years after LCATD surgery (median, 1.2 years; range, 0.46-3.07 years). Of these, the subaortic stenosis was identified in 2 patients before LCATD surgery. Evidence of subaortic stenosis after PA banding developed in 4 patients, who underwent subaortic resection at the time of the second-stage surgery. No subaortic resections occurred after the secondstage surgery.

Children who underwent LCATD and achieved hospital discharge were inpatients $29.2 \pm 28.9$ days (median, 19 days; range, 7-138 days) from LCATD surgery. One patient underwent truncus arteriosus repair 4 days after LCATD surgery and was discharged from the hospital 21 days after LCATD surgery.

\section{DISCUSSION}

The optimal surgical technique to repair IAA remains a matter for debate. Although the Indiana University School of Medicine prefers the LCATD technique, many centers use primary anastomosis or aortic arch advancement. ${ }^{11-13}$ Likewise, the Indiana University School of Medicine uses primary repair for more complex lesions, including dextro-transposition of the great arteries, truncus arteriosus, and hypoplastic left heart syndrome.

In the primary anastomosis technique, the ascending aorta and its branches are mobilized along with the ductus arteriosus and descending aorta via a median sternotomy. The ductus is ligated and divided after commencing cardiopulmonary bypass, and ductal tissue is excised. One or 2 periods of hypothermic circulatory arrest may be required, 
TABLE 1. Patient characteristics: Mean \pm standard deviation or n $(\%)$

\begin{tabular}{lc}
\hline & Total $(\mathbf{n}=\mathbf{4 7})$ \\
\hline Male & $30(63.8 \%)$ \\
Body weight $(\mathrm{kg})$ & $3.0 \pm 0.6$ \\
Type of aortic arch interruption & \\
Type A & $1(2.1 \%)$ \\
Type B & $46(97.9 \%)$ \\
Type C & $0(0 \%)$ \\
Associated structural cardiac anomalies & \\
Patent ductus arteriosus & $47(100 \%)$ \\
VSD & $46(97.9 \%)$ \\
Atrial septal defect & $27(57.4 \%)$ \\
Bicuspid or unicommisural aortic valve & $19(40.4 \%)$ \\
Subaortic stenosis & $12(25.5 \%)$ \\
Aortic stenosis & $3(6.4 \%)$ \\
Aberrant right subclavian artery & $3(6.4 \%)$ \\
Truncus arteriosus & $2(4.3 \%)$ \\
Taussig-Bing DORV & $2(4.3 \%)$ \\
Double-inlet left ventricle & $2(4.3 \%)$ \\
Hypoplastic right ventricle & $1(2.1 \%)$ \\
Double-outlet right ventricle & $1(2.1 \%)$ \\
Hypoplastic left ventricle & $1(2.1 \%)$ \\
L-transposition of the great arteries & $1(2.1 \%)$ \\
D-transposition of the great arteries & $1(2.1 \%)$ \\
Mitral atresia & $1(2.1 \%)$ \\
Vascular ring & $1(2.1 \%)$ \\
\hline VSD, Vetic ser &
\end{tabular}

$V S D$, Ventricular septal defect; $D O R V$, double-outlet right ventricle.

depending on the approach needed to close the VSD and associated intracardiac defects. ${ }^{14}$ Proponents of this approach endorse the advantage that it allows for adequate growth potential of the aortic arch. ${ }^{15}$ In addition, the midline approach enables a complete, 1-stage repair, allowing for repair of associated cardiac anomalies.

Postoperative complications with this procedure are well documented. Bronchial compression may result from tension at the anastomotic site secondary to inadequate

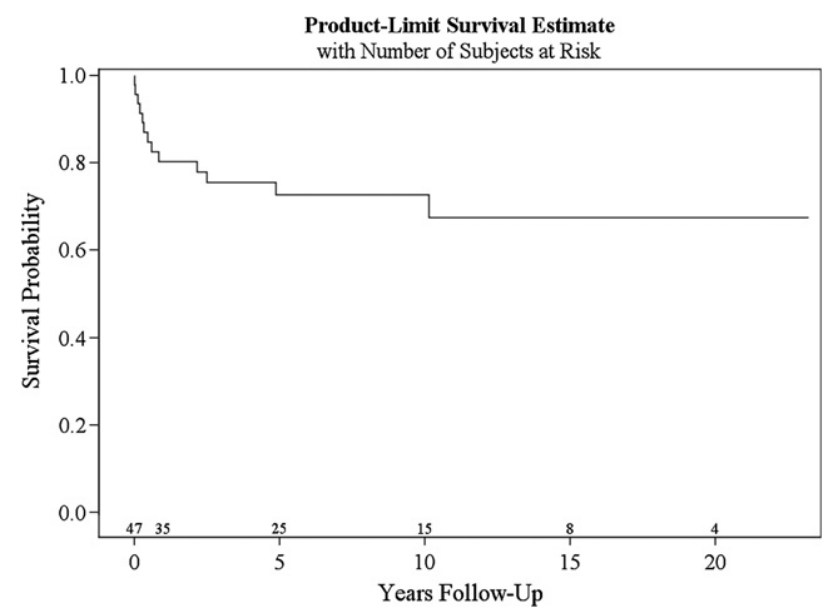

FIGURE 2. Kaplan-Meier survival for all patients.

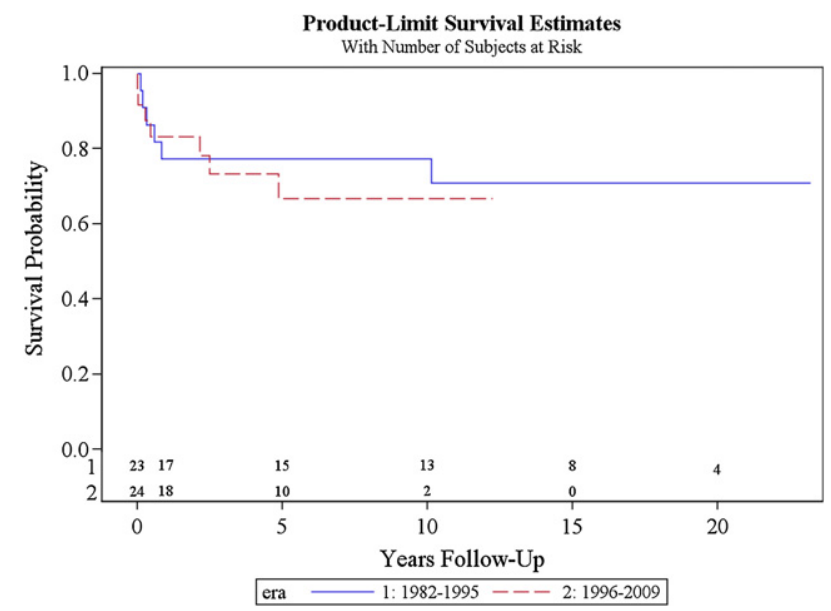

FIGURE 3. Kaplan-Meier survival curve for all patients (stratified by era).

mobilization of the aorta. ${ }^{6,13,16}$ The increased posterior and inferior traction of the aorta on the left main bronchus have necessitated aortopexy or placement of an interposition graft. ${ }^{16,17}$ Bleeding also is more likely in the postoperative period because of increased tension of the aortic arch anastomosis. ${ }^{14}$ Reports, including the latest 472 patient multi-institutional Congenital Heart Surgeons' Society (CHSS) study, have suggested that the direct anastomosis technique results more frequently in aortic arch obstruction compared with other methods of repair. ${ }^{12,18,19}$ The reported incidence of persistent or recurrent arch obstruction ranges from $0 \%$ to $50 \%$.

A recent report describes a new technique for IAA in which the anterior wall of the PA is excised and tailored to reestablish aortic continuity with an autologous tube. ${ }^{20}$ It has been referred to as the "Neville tube." Outcomes of this technique will warrant consideration as more experience is acquired.

We report a 15-year freedom from aortic arch reintervention rate of $57.4 \%$ that is comparable to a recent report by Hussein and colleagues, ${ }^{21}$ who described a $51 \%$ freedom from aortic arch obstruction in the setting of direct endto-side anastomosis. However, Morales and colleagues ${ }^{22}$ reported a 5-year freedom from aortic arch reintervention rate of $100 \%$ with the aortic arch advancement technique. Their study used an actuarial method for the statistical analysis. By using a Kaplan-Meier estimation method but excluding nonsurvivors, our 5-year freedom from reintervention rate is $66.3 \%$ (95\% CI, 47.4-79.7).

The LCATD technique presents some advantages over direct anastomosis. By providing a tension-free anastomosis, bronchial compression is avoided, as seen in this series. Nevertheless, bronchial compression was avoided in the arch advancement series reported by Morales and colleagues. ${ }^{22}$ This was achieved with extensive mobilization of the descending aorta. In addition, we report a $13 \%$ incidence of subaortic resection at the time of the second-stage 
TABLE 2. Mortality data

\begin{tabular}{|c|c|c|c|c|c|c|c|}
\hline Diagnoses & $\begin{array}{r}\text { Timing } \\
\text { of death }\end{array}$ & Cause & $\begin{array}{c}\text { Age at } \\
\text { death } \\
(\mathbf{m o})\end{array}$ & $\begin{array}{c}\text { Time from } \\
\text { LCATD } \\
\text { (mo) } \\
\end{array}$ & Last surgery & $\begin{array}{c}\text { Time from } \\
\text { last surgery } \\
(\mathbf{m o}) \\
\end{array}$ & $\begin{array}{c}\text { Hospital } \\
\text { discharge } \\
\text { after LCATD } \\
\end{array}$ \\
\hline $\begin{array}{l}\text { IAA-B, VSD, } \\
\text { DiGeorge } \\
\text { syndrome }\end{array}$ & Operative & Sepsis & 0.39 & 0.16 & LCATD; PAB & 0.16 & No \\
\hline IAA-B, VSD & Operative & $\begin{array}{l}\text { Intraoperative death; } \\
\text { severe residual arch } \\
\text { obstruction; low-output } \\
\text { heart failure }\end{array}$ & 0.66 & 0.33 & DKS Sano & 0.00 & No \\
\hline $\begin{array}{l}\text { IAA-B, VSD, DILV, } \\
\text { L-TGA, hypoplastic AA }\end{array}$ & Operative & Central line infection & 1.48 & 1.31 & LCATD; PAB & 1.31 & No \\
\hline IAA-B, VSD & Late & $\begin{array}{l}\text { Low-output heart failure } \\
\text { (ECMO) }\end{array}$ & 3.48 & 3.25 & $\begin{array}{l}\text { VSD, PAB removal, } \\
\text { recoarctation } \\
\text { patch augmentation }\end{array}$ & 0.13 & Yes \\
\hline IAA-B, VSD & Late & Respiratory failure & 4.01 & 3.91 & LCATD; PAB & 3.91 & Yes \\
\hline $\begin{array}{l}\text { IAA-B, VSD, truncus } \\
\text { arteriosus }\end{array}$ & Late & $\begin{array}{l}\text { Intraoperative death; } \\
\text { low-output heart failure }\end{array}$ & 4.04 & 3.94 & $\begin{array}{l}\text { PAB removal, } \\
\text { truncus repair }\end{array}$ & 1.68 & Yes \\
\hline $\begin{array}{l}\text { IAA-B, VSD, VACTERL } \\
\text { association }\end{array}$ & Operative & Respiratory failure & 5.75 & 5.55 & LCATD; PAB & 5.55 & No \\
\hline $\begin{array}{l}\text { IAA-B, VSD, DiGeorge } \\
\text { syndrome }\end{array}$ & Late & Pneumonia & 6.97 & 6.90 & VSD, PAB removal & 2.17 & Yes \\
\hline $\begin{array}{l}\text { IAA-B, VSD, DiGeorge } \\
\text { syndrome }\end{array}$ & Late & Pneumonia & 10.02 & 9.86 & $\begin{array}{l}\text { VSD, PAB removal, } \\
\text { PFO closed }\end{array}$ & 5.78 & Yes \\
\hline $\begin{array}{l}\text { IAA-B, multiple VSDs, } \\
\text { DiGeorge syndrome }\end{array}$ & Late & Sepsis & 25.99 & 25.89 & VSD, PAB removal & 14.49 & Yes \\
\hline IAA-B, VSD, DILV, D-TGA & Late & Respiratory failure & 30.19 & 30.06 & Extracardiac Fontan & 2.66 & Yes \\
\hline IAA-B, VSD & Late & Sudden death & 59.76 & 58.38 & VSD, PAB removal & 45.14 & Yes \\
\hline $\begin{array}{l}\text { IAA-B, VSD, DORV, } \\
\text { subaortic stenosis }\end{array}$ & Late & Transplant rejection & 118.51 & 118.47 & Heart transplant & 10.35 & Yes \\
\hline
\end{tabular}

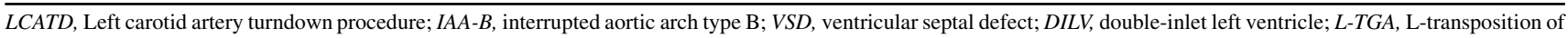
the great arteries; $A A$, aortic arch; VACTERL, disorder that involves abnormalities of the vertebrae, anus, heart, trachea, kidneys and limbs; $D$-TGA, D-transposition of the great arteries; DORV, double-outlet right ventricle; $E C M O$, extracorporeal membrane oxygenation; PAB, pulmonary artery banding; $D K S$ Sano, Damus-Kaye-Stansel with Sano modification; $P F O$, patent foramen ovale.

repair. Prior studies have reported rates of reoperation for left ventricular outflow obstruction from $18 \%$ to $34 \% .^{22,23}$ A strategy we use to reduce the risk of

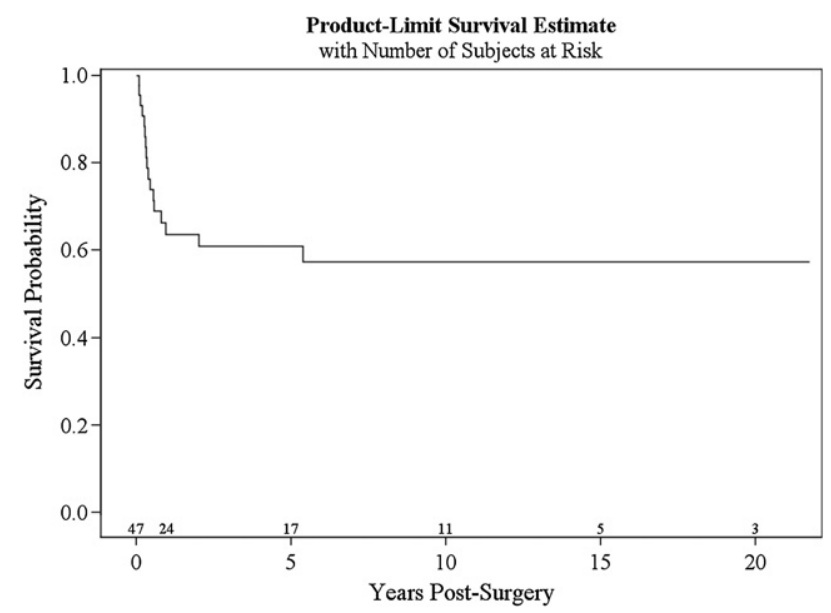

FIGURE 4. Freedom from aortic arch reintervention or reoperation (all patients). subaortic obstruction is to limit the time of PA banding to between 3 and 9 months when possible. Although 7 outliers underwent PA debanding more than 2 years after the initial surgery because of conditions such as pulmonary hypertension, $20 \quad(66 \%)$ underwent the second-stage surgery within 1 year of the LCATD. Patients who underwent subaortic resection completed the second stage $1.6 \pm 0.9$ years after LCATD.

The avoidance of circulatory arrest and cardiopulmonary bypass in the neonatal period is perhaps the most important consideration with the LCATD technique. In a recent analysis of neonates with IAA who underwent surgical repair, longer circulatory arrest times predicted lower mental development. ${ }^{24}$ Regional perfusion techniques have been asserted as improvements to circulatory arrest with respect to neurodevelopmental outcomes ${ }^{25-27}$; however, recent studies have not demonstrated differences between the 2 modalities. ${ }^{28-30}$ Although neurologic outcomes were not a primary end point in our study, a lack of neurologic deficits, seizures, and growth disturbances has been described in prior reports using the LCATD technique. ${ }^{10}$ 
Our operative survival and late survival for the LCATD technique are $91 \%$ and $72 \%$, respectively. The aforementioned single-stage experience reported by Morales and colleagues $^{22}$ describes comparable survival, with 30-day survival at $93 \%$ and 5 -year survival at $76 \%$. Mainwaring and Lamberti ${ }^{23}$ report a 2-stage approach with 1 - and 5 -year survival at $85 \%$ and $81 \%$, respectively. The late survival reported in the CHSS study is similar at $67 \%$, which included IAA types A and B. The CHSS reported a 56\% late survival for patients with type $\mathrm{B}$, which was the IAA type in all but 1 patient in our series. ${ }^{18}$ Their analysis importantly identified IAA type B as an independent risk factor for mortality. It was of interest that although this subgroup made up $70 \%$ of the CHSS patient population, IAA type B represented $97.9 \%$ of our population.

\section{Study Limitations}

This is a retrospective review that covers more than 25 years. Although continued experience with a procedure may lead to significant changes in outcome over time, we demonstrated no significant change in outcome when accounting for different surgical eras. Direct comparison with other surgical modalities for this disease is limited because our center has favored the LCATD for IAA in greater than $95 \%$ of cases. As such, the primary mode of comparison is to compare outcomes with those of other centers, as reported in this study.

A potential disadvantage of this procedure is the sacrifice of 1 carotid artery. Although no complications of this have been directly observed, more specific evaluation of this element would be warranted. It is important to also recognize that this approach requires 2 surgeries compared with the more common single-stage approach. Nevertheless, a second surgery is frequently required in single-stage repair for subaortic stenosis, reported at $18 \%$ to $34 \%$ in some series. $^{22,23}$ In our series, we present 2 additional operative mortalities that occurred relative to the second-stage surgery. Despite this additional operative risk, the intention of the 2-stage approach in our center is to limit cardiopulmonary bypass exposure in the newborn period with outcomes comparable to the single-stage approach.

\section{CONCLUSIONS}

The optimal method for aortic arch repair will likely continue to be unresolved without a multicenter randomized controlled trial. This study represents the largest reported series of the LCATD technique. Our data demonstrate that the LCATD technique has operative and late survivals for IAA type B that are similar to those for other reported methods. Although there still remains a significant reintervention rate for recurrent arch obstruction, the intervention rate for subaortic obstruction was low at $13 \%$ in our series compared with the $25 \%$ to $40 \%$ subaortic obstruction rate reported in other series. ${ }^{12}$ We contend that the reduced exposure to circulatory arrest and cardiopulmonary bypass in the newborn period and lower incidence of bronchial compression and reoperation for subaortic resection offset the higher reintervention rate and make this a reasonable approach to IAA repair.

The authors thank Katie Lane for the statistics expertise and assistance with the Biomedical Statistics department at Indiana University.

\section{References}

1. Steidele RJ. Samml Chir u Med Beob (Vienna). 1778;2:114.

2. Van Praagh R, Bernhard WF, Rosenthal A, Parisi LF, Fyler DC. Interrupted aortic arch: surgical treatment. Am J Cardiol. 1971;27:200-11.

3. Lang P, Freed MD, Rosenthal A, Castaneda AR, Nadas AS. The use of prostaglandin e1 in an infant with interruption of the aortic arch. J Pediatr. 1977;91:805-7.

4. Olley PM, Coceani F, Bodach E. E-type prostaglandins: a new emergency therapy for certain cyanotic congenital heart malformations. Circulation. 1976;53:728-31.

5. Merrill DL, Webster CA, Samson PC. Congenital absence of the aortic isthmus report of a case with successful surgical repair. J Thorac Surg. 1957;33:311-20.

6. Tlaskal T, Hucin B, Hruda J, Marek J, Chaloupecky V, Kostelka M, et al. Results of primary and two-stage repair of interrupted aortic arch. Eur J Cardiothorac Surg. 1998;14:235-42.

7. Schreiber C, Eicken A, Vogt M, Gunther T, Wottke M, Thielmann M, et al. Repair of interrupted aortic arch: results after more than 20 years. Ann Thorac Surg. 2000; 70:1896-900

8. Vouhe PR, Mace L, Vernant F, Jayais P, Pouard P, Mauriat P, et al. Primary definitive repair of interrupted aortic arch with ventricular septal defect. Eur J Cardiothorac Surg. 1990;4:365-70.

9. Celoria GC, Patton RB. Congenital absence of the aortic arch. Am Heart J. 1959; 58:407-13.

10. Brown JW, Ruzmetov M, Okada Y, Vijay P, Rodefeld MD, Turrentine MW. Outcomes in patients with interrupted aortic arch and associated anomalies: a 20 year experience. Eur J Cardiothorac Surg. 2006;29:666-74.

11. Odim JN, Laks H, Drinkwater DC Jr, George BL, Yun J, Salem M, et al. Staged surgical approach to neonates with aortic obstruction and single-ventricle physiology. Ann Thorac Surg. 1999;68:962-8.

12. Sell JE, Jonas RA, Mayer JE, Blackstone EH, Kirklin JW, Castaneda AR. The results of a surgical program for interrupted aortic arch. J Thorac Cardiovasc Surg. 1988;96:864-77.

13. Serraf A, Lacour-Gayet F, Robotin M, Bruniaux J, Sousa-Uva M, Roussin R, et al. Repair of interrupted aortic arch: a ten-year experience. J Thorac Cardiovasc Surg. 1996;112:1150-60.

14. Jonas RA, DiNardo JA. Comprehensive Surgical Management of Congenital Heart Disease. London, England: Oxford University Press; 2004.

15. Monro JL, Delany DJ, Ogilvie BC, Salmon AP, Keeton BR. Growth potential in the new aortic arch after non-end-to-end repair of aortic arch interruption in infancy. Ann Thorac Surg. 1996;61:1212-6.

16. Sakai T, Miki S, Ueda Y, Tahata T, Ogino H, Morioka K, et al. Left main bronchus compression after aortic reconstruction for interruption of aortic arch. Eur J Car diothorac Surg. 1995;9:667-9.

17. Mishra PK. Management strategies for interrupted aortic arch with associated anomalies. Eur J Cardiothorac Surg. 2009;35:569-76.

18. McCrindle BW, Tchervenkov CI, Konstantinov IE, Williams WG, Neirotti RA, Jacobs ML, et al. Risk factors associated with mortality and interventions in 472 neonates with interrupted aortic arch: a Congenital Heart Surgeons Society study. J Thorac Cardiovasc Surg. 2005;129:343-50.

19. Oosterhof T, Azakie A, Freedom RM, Williams WG, McCrindle BW. Associated factors and trends in outcomes of interrupted aortic arch. Ann Thorac Surg. 2004; 78:1696-702.

20. Bergoend E, Bouissou A, Paoli F, Roullet-Renoleau N, Duchalais A, Neville P. A new technique for interrupted aortic arch repair: the Neville tube. Ann Thorac Surg. 2010;90:1375-6.

21. Hussein A, Iyengar AJ, Jones B, Donath SM, Konstantinov IE, Grigg LE, et al Twenty-three years of single-stage end-to-side anastomosis repair of interrupted aortic arches. J Thorac Cardiovasc Surg. 2010;139:942-7, 949; discussion 948.

22. Morales DL, Scully PT, Braud BE, Booth JH, Graves DE, Heinle JS, et al. Interrupted aortic arch repair: aortic arch advancement without a patch minimizes arch reinterventions. Ann Thorac Surg. 2006;82:1577-84. 
23. Mainwaring RD, Lamberti JJ. Mid- to long-term results of the two-stage approach for type b interrupted aortic arch and ventricular septal defect. Ann Thorac Surg. 1997;64:1782-6.

24. Joynt CA, Robertson CM, Cheung PY, Nettel-Aguirre A, Joffe AR, Sauve RS, et al. Two-year neurodevelopmental outcomes of infants undergoing neonatal cardiac surgery for interrupted aortic arch: a descriptive analysis. J Thorac Cardiovasc Surg. 2009;138:924-32.

25. Williams GD, Ramamoorthy C. Brain monitoring and protection during pediatric cardiac surgery. Semin Cardiothorac Vasc Anesth. 2007;11:23-33.

26. Su XW, Guan Y, Barnes M, Clark JB, Myers JL, Undar A. Improved cerebral oxygen saturation and blood flow pulsatility with pulsatile perfusion during pediatric cardiopulmonary bypass. Pediatr Res. 2011;70:181-5.
27. Nelson DP, Andropoulos DB, Fraser CD Jr. Perioperative neuroprotective strategies. Semin Thorac Cardiovasc Surg Pediatr Card Surg Annu. 2008;49-56.

28. Visconti KJ, Rimmer D, Gauvreau K, del Nido P, Mayer JE Jr, Hagino I, et al. Regional low-flow perfusion versus circulatory arrest in neonates: one-year neurodevelopmental outcome. Ann Thorac Surg. 2006;82:2207-13.

29. Tabbutt S, Gaynor JW, Newburger JW. Neurodevelopmental outcomes after congenital heart surgery and strategies for improvement. Curr Opin Cardiol. 2012; 27:82-91.

30. Dominguez TE, Wernovsky G, Gaynor JW. Cause and prevention of central nervous system injury in neonates undergoing cardiac surgery. Semin Thorac Cardiovasc Surg. 2007;19:269-77. 